\title{
ARports of HAtedical Sorieties.
}

\author{
Berkshire District MEdical society. J. F. A. ADAMS, M.D., pitTSField, \\ SECRETARY.
}

Frbruary 28th, 1872.-Dr. Mercer, of Pittsfield, reported a case of Aneurism of the Aortic Arch, and exhibited the specimen. The patient was a man, aged 46 , who had been dropsical for two months. $A$ blowing murmur could be heard over the region of the heart, extending along the carotids and subclavians. At the autopsy, atheromatous disease of the aorta was discovered; and an aneurismal sac, involving the two outer coats, as large as a hen's egg, was found at the right side of the arch, connected with it by a rough, bony orifice, as large as the calibre of the aorta.

- Dr. Adams, of Pittsfield, exhibited the Foetus of a Deer lately presented to the Berkshire Athenæum. The doe was shot in the Adirondacks last summer, and was suckling a fawn at the time. On being opened, a foetus, dry and shrivelled, distorted, and consisting only of bone and a little hardened tissue, was found adherent to the abdominal walls, against the short ribs on the right side, and unconnected with the uterus. It was a case of extra-uterine fotation, with recovery.

Dr. Adams also reported a case of Gun-shot Wound of the Abdomen. The patient was a very strong young man, aged 33 . 'ihe ball, a No. 1 pistol slug, fired from a Smith \& Wesson revolver, entered the body, over the sixth costal cartilage, on the right side, passed downward and backwards, penetrating the seventh costal cartilage, and thence into the abdominal cavity. A little fresh blood was vomited at first; and the following day a quantity of black vomit was raised. Symptoms of peritonitis were rapidly developed, with excruciating pain, but the symptoms were all relieved by the free use of morphia. The patient lived fiftecn days, retaining his strength remarkably to the last. 'Twelve hours before death, he began suddenly to vomit large quantities of blood, followed by black vomit, and rapidly sank. There was extreme tympanites, and the pain was chiefly referred to the umbilicus and right hypochondrium. He took, daily, from one to grains of morphia hypodermically; and half a grain every three hours by the mouth. 'This was enough to mitigate the pain, but he had very little sleep.

At the autopsy, the bullet was found to have penetrated the liver from above downwards, its track being two and a half inches long; then, passing close to the gall-bladder, to have passed through the duodenum, making two distinct orifices, an inch below the pylorus; then, still passing downward, to have penetrated the ileum at about the middle, finally lodging against the crest of the right ilium, behind the edge of the psoas muscle. The bullet was not bruised at all ; it was surrounded by a great mass of lymph, and the peritoneum contained a quantity of blood.

Dr. Adams reported $A$ Case of Hallucination in an old gentleman, aged 84 , who had, for forty years, firmly believed that his stomach was inhabited by a lizard. His symptoms were those of valvular disease of the heart and chronic gastritis. IIs death was sudden, although he had been very feeble for a long time. At the autopsy, the heart was found 
hypertrophied, with ossification and contraction of tho semilunar, mitral and tricuspid valves; and the aorta and larger arteries were also ossified. The stomach was contracted, its walls much thickened, its lining menbrane red, thick and vascular. The lizard was not discovered.

May 29th, 1872. - Dr. Isawrence, of North Adams, reported several cases of Cerebro-spinal Meningitis, recently under his caro. Ile has had about a dozen in all, of which one was fatal. In all cases there was headache, with pain in the back and limbs, and in several there was screaming. His treatment had chiefly been bromide of potassium and opium. In the fir'st few cases he did not use opium, but found it latterly to be the only means of producing quiet. Chloral did not have a quieting effect. Counter-irritation was effected by blisters and croton oil.

Dr. Babbit, of North Adams, said he had also had several cases of cerebro-spinal meningitis lately. In some of them screaming was a prominent symptom. In the case of one young lady, a choraic action of the head remained after recovery. The cases among infants, attended with convulsions, have generally proved fatal.

Colloiel Disease of Slomach - Dr. Babbitt also reported the case of Prof. Ilopkins, of Williams College. ITe had long suffered from dyspepsia, loss of appetite and diarlioea, and had a tumor, which could be distinctly felt, in the region of the stomach. At the autopsy, a tumor was found, involving the lesser curvature of the stomach, eight inches in length, extending fiom the pylorus upward, averaging three fourths of an inch in thickness, and involving the whole thickness of the wall of the stomach. It was not examined microscopically, but was supposed to be colloid in structure.

Jurr 31st, 1872.-Fracture of Skull.-Dr. Paddock, of Pittsfield, reported the case of a man, 25 years of age, who had been killed by a blow upon the head from a base-ball. After receiving the blow, he walked about town for half an hour or more, then went to his boardinghouse, and up stairs to bed. His companions observed that he made incoherent answers to their questions, and complained of pain in the head. During the night, he was heard to moan. When called in the morning, he was found to be dying, and died before a physician arrived. An autopsy was made, and a fracture of the skull discovered, beginning at the junction of the coronal with the sagittal suture, and extending down the right side, opening the coronal suture for about an inch, and then passing through the parietal and temporal bones nearly to the car. Beneath the fiacture was found a clot of blood, weighing four ounces. The man was intoxicated when he received the blow, which was a very heavy one, the bat being held in both hands, and laid on with vigor.

Oct 30th, 1872.- Epidemic of Diphtheria.-Dr. Wilcox, of Lee, described an epidemic of diphtheria now provailing in Lee. IHe had seen thirty-two cases, of which six had died. It was chicfly confined to children, and the youngest patients have the disease the most severely. The epidemic followed immediately upon one of scarlatina, and had been most prevalent in damp places, especially in old houses. Lee is a damp town, and the paper-mill operatives are over-crowded and not over-cleauly. In all cases, there was great depression. The membrane usually forms first upon the tonsils. In the fatal cases, death generally occurred in about eight days, and results fiom an extension of the deposit to the trachea. During the epidemic, Dr.

Vol, Lxxxvir. No. 6A 
Wilcox had seen two cases of common membranous croup, unconnected with diphtheria.

Dr. Mercer, of Pittsfield, remarked that he had lately had several fatal cases of membranous croup in young children with great depression.

Intra-cranial Abscess.-Dr. Davis, of Lcnox, reported a case of headache, which he attributed to auscess of the internal car, pressing upon the third branch of the fifth nerve. The case passed into the hands of a quack, who pronounced it catarrh of the ear. The patient soon died; and, at the autopsy, an intra-cranial abscess was found pressing the brain to one side.

Cerebral Congestion-Pavaplegia.-Dr. Wilcox, of Lee, exhibited to the Society a young man suffering from paralysis of the left arm, accompanied with swelling, anæsthesia and formication. The paralysis extended over the shoulder anteriorly. Thero was a tender spot over the middle cervical vertebra. The arm was as warm as its fellow. Similar symptoms attacked the left foot and $\mathrm{leg}$, a few days later, but soon passed off. The history of the case is as follows : The patient was first seen by Dr. Wilcox on Sept. 22d. Until noon of that day, he had appeared perfectly well, although on the preceding day he was seen, while running in the woods, to strike his head against a tree with violence. Dr. Wilcox found him wildly delirious, and strapped to the bed by feet and wrists. Quiet was produced by a hypodermic injection of morphia. The delirium returned during the night, but there wero lucid intervals when the patient appeared well. The pulse was normal; skin cool and moist; tongue coated. On the second day, the morphia was repeated. On the third day, Dr. Paddock was called in consultation, and advised cathartic medicine, which was given, followed by great relief; but the attacks of delirium continued less fiequently for a week. The patient retained his strength, and, unless confined and watched, would escape from the house and wander about. for hours. During the lucid intervals, he was depressed. $\Lambda$ t the end of the week, he was lost sight of ; but reaippeared the preceding day, having been cared for at a friend's house in the meantime. He was not aware of having had any crazy spells of late; but the paralysis had been coming on gradually for a fortnight. Dr. Wilcox considered the case in the first instance as congestion of the brain, caused by the blow upon the head.

\section{ZBibliogxapyícal $\$$ otícs.}

A. New Method for Ixtraction of Cataract. By R. LinBreich, Ophthalmic Surgeon and Lecturer at St. Thomas's IIospital.

$\Lambda$ NEAT pamphlet with the above title has been published by Messrs. Claxton, Remsen and Haffelfinger, of Philadelphia. There can bo no question that this plan has immense advantages both over the former methods of flap extraction and the unscientific " new method" by peripheral incision proposed by Graefe, and largely adopted on his authority, but now admitted to have been a wide deviation from the true principles of cataract operation. We quote the words of the author, as a brief description of his method. "To avoid the disadvantages in Graefe's operation arising out of the peripheral position of 